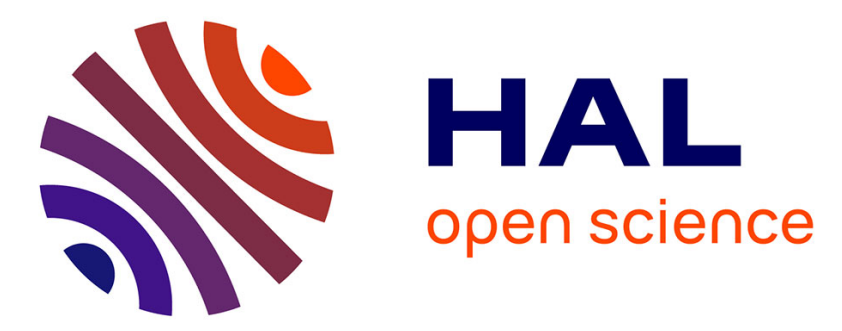

\title{
Basic aspects regarding irregular metal surfaces and their application in electrochemistry
}

\author{
A. Arvia, R. Salvarezza
}

\section{To cite this version:}

A. Arvia, R. Salvarezza. Basic aspects regarding irregular metal surfaces and their application in electrochemistry. Journal de Physique IV Proceedings, 1994, 04 (C1), pp.C1-39-C1-53. 10.1051/jp4:1994103 . jpa-00252445

\section{HAL Id: jpa-00252445 https://hal.science/jpa-00252445}

Submitted on 1 Jan 1994

HAL is a multi-disciplinary open access archive for the deposit and dissemination of scientific research documents, whether they are published or not. The documents may come from teaching and research institutions in France or abroad, or from public or private research centers.
L'archive ouverte pluridisciplinaire HAL, est destinée au dépôt et à la diffusion de documents scientifiques de niveau recherche, publiés ou non, émanant des établissements d'enseignement et de recherche français ou étrangers, des laboratoires publics ou privés. 


\title{
Basic aspects regarding irregular metal surfaces and their application in electrochemistry
}

\author{
A.J. ARVIA and R.C. SALVAREZZA
}

Instituto de Investigaciones Fisicoquímicas Teóricas y Aplicadas (INIFTA), Facultad de Ciencias Exactas, Universidad Nacional de La Plata, Sucursal 4, Casilla de Correo 16, 1900 La Plata, Argentina

\begin{abstract}
The topography and other properties related to disordered metal surfaces play an important role in deposition, corrosion and growth phenomena.

Metal surfaces resulting from columnar or dendritic metal deposits can be taken as models of anisotropic and isotropic strong surface disorder, respectively. The topography of rough columnar surfaces can be determined by scanning tunneling microscopy at different scales and described by means of the dynamic scaling theory. Roughness relaxation kinetics can be followed by electrochemical techniques and interpreted through a coalescence-type mechanism. Typical examples of electrochemical reactions at this type of electrodes are presented.

The study of the electrochemical formation of 3D or 2D metal dendrites provides basic information about the development of either diffusion limiting aggregation-type or dense radial patterns and the design and working condition ranges. In this case, the influence of convection and, particularly, that of the relative contribution of migration and diffusion on determining the topography of the object has been established. A generalized model based upon a Monte Carlo simulation has accounted for the experimental results.
\end{abstract}

RÉSUMÉ

La topographie et les autres propriétés liées aux surfaces métalliques désordonnées jouent un rôle important dans la déposition, la corrosion et les phénomènes de croissance. Les surfaces métalliques provenant de dépôts métalliques dont les formes sont des colonnes ou dendrites peuvent être considérées comme des modèles d'un fort désordre superficiel, anisotropique et isotropique, respectivement.La topographie des surfaces avec des colonnes peut être déterminée par STM à des échelles différentes et décrite par la théorie de "dynamic scaling".

La cinétique de relaxation de la rugosité peut être suivie par des techniques électrochimiques et interprétée par un mécanisme de coalescence. On présente des exemples caractéristiques de réactions électrochimiques à ce genre d'électrodes. L'étude de la formation électrochimique de dendrites métalliques de types 3D ou 2D donne des informations de base sur le développement soit d'aggrégats limités par la diffusion, soit de structures radiales compactes, de même que des informations sur la forme et les conditions detravail. Dans ce cas, l'influence de la convection a été déterminée, et notamment, l'influence de la contribution relative de la migration et de la diffusion sur la topographie superficielle. Un modèle généralisé basé sur une simulation de type Monte Carloa permis de rendre compte des résultats expérimentaux. 


\section{INTRODUCTION}

Irregular surfaces and interfaces exists on all scales. From heterogeneous catalysis and electrocatalysis standpoints irregularities at the atomic level are relevant to define electronic energy distribution at surface sites, but irregularities in the $\mu \mathrm{m}$ range are important to determine the accessibility of reactants to those surface sites. Accordingly, the efficiency of a surface for a particular reaction depends on a compromise between quality and quantity of reacting sites and surface topography. Consequently, the study of irregular surfaces comprises the geometric description, the kinetics of the formation and relaxation processes and the surface properties for different reactions.

In general, irregular surfaces of solids involve a continuous or a discontinuous disorder phase. In a continuous phase the surface disorder can be described as no disordered (smooth surfaces), weakly disordered (stepped or reconstructed surfaces), and strongly disordered surfaces (Fig.1) (1). Strong disorder comprises both anisotropic strong disorder, as in rough surfaces, and isotropic strong disorder as in dendritic surfaces.

a

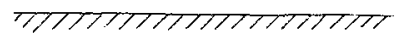

b
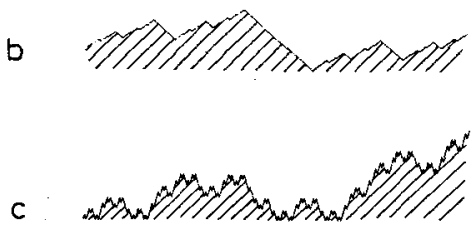

d

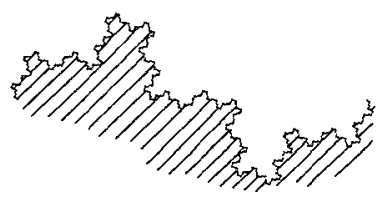

Figure 1. Schemes of different types of disorder (a) no disorder, (b) weak disorder, (c) anisotropic strong disorder (self-affine), (d) isotropic strong disorder (self-similar) Reproduced with permission from Ref. (1)

Strongly disordered surfaces can be better described in terms of fractal rather than euclidean geometry (2). The fractal approach to the study of rough surfaces provides quantitative information about the degree of surface disorder, the mechanism of surface growth and the kinetics of reactions on strongly disordered surfaces.

This work presents recent progress in the knowledge of strongly disordered metal electrode surfaces. Experimental systems used as models to study both isotropic and anisotropic strong disorders are presented. Available methods for surface characterization in terms of fractal geometry are discussed. 


\section{ANISOTROPIC STRONG DISORDER :}

\subsection{Rough electrodes}

The term rough surface has been proposed for an irregular surface on which there are no overhanging regions or where at least these regions do not dominate the scaling properties (3). Thus, the absence of overhangs implies the anisotropic character of the surface disorder. In terms of fractal geometry these surfaces are called "self-affine fractals" (2).

Rough surfaces can be created, for instance, by either adding to or removing material from flat substrates (4). Typical examples of rough electrode surfaces created by addition of material at high rates are shown in Fig. 2 . The surfaces of vapour deposited gold on glass, electrodeposited gold on gold wire cathodes, and poly(o-toluidine) grown on gold single crystals exhibit a common topography that consists of rounded elements with branched voids when imaged at the nanometer size by scanning tunneling microscopy (STM). In all these cases the electrode cross sections imaged by scanning electron microscopy (SEM) have revealed a uniform material density indicating a non-fractal volume. Despite the difference in the nature and growth mechanism of these deposits and the different nature of the subtrates, the topography of these deposits looks very similar. It appears that different systems evolve spontaneously to common topographic patterns. In fact, both theoretical considerations and experimental results have indicated that surfaces grown at high rate reach a steady state pattern characterized by universal self-affine fractal properties (5).

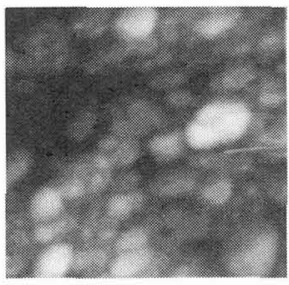

a

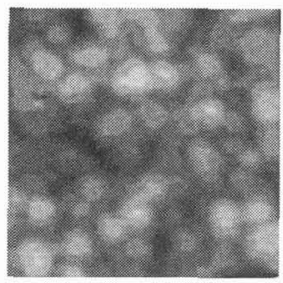

b

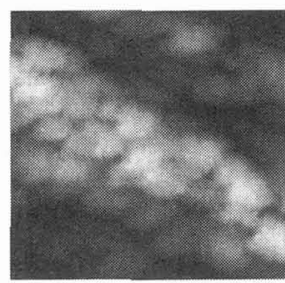

$\mathrm{c}$

Figure 2. STM images (top view) of different deposits. a) $300 \times 300 \mathrm{~nm}^{2}$, vapour deposited gold $f i l m$ on glass, b) $300 \times 300 \mathrm{~nm}^{2}$, electrodeposited gold film on a gold wire cathode, c) $250 \times 250 \mathrm{~nm}^{2}$, electrodeposited poly(o-toluidine) on a gold single crystal.

\subsection{The dynamic scaling theory.}

The dynamic scaling theory provides a useful approach to describe rough surfaces. This theory starts to consider the development of a $2 \mathrm{D}$ surface contour on a flat $1 \mathrm{D}$ surface of length $\mathrm{L}$ at $\mathrm{time} t=0(4)$, and the rough surface continues 
growing in height, $h$, a single direction normal to $L$, without producing overhangs. Then, the instantaneous surface height can be described by the function $h(x, t)$.

The instantaneous surface width, $\xi(L, t)$ which is taken as a measure of surface roughness, is defined by the root mean square of height fluctuations (4)

$$
\xi(L, t)=\left[1 / L \sum\left[h\left(x_{1}\right)-\bar{h}\right]^{2}\right]^{1 / 2}
$$

where $\bar{h}$ is the average height in direction normal to the surface. The dependence of $\xi(L, t)$ on $t$ and $L$ is given by:

$$
\xi(L, h) \propto L^{\alpha} f(x)
$$

where $f(x)=\vec{h} / L^{\gamma}$. The function $f(x)$ has the following properties: $f(x)=$ const for $x$ $\Rightarrow \infty$ and $f(x)=x^{\alpha / \gamma}$ for $x \Rightarrow 0$. Initially $\xi$ increases with time as random fluctuations do according to

$$
\xi(L, t \Rightarrow 0) \propto t^{\beta}
$$

where the exponent $\beta$ decribes roughness kinetics along the growth directions. After a sertain time (or thickness) a steady state surface contour is reached.

$$
\xi(L, t \Rightarrow \infty) \propto L^{\alpha}
$$

The surface under steady state conditions becomes a scale invariant self-affine fractal and the exponent $\alpha$ becomes a relevant parameter to describe roughness $(4,5)$. This exponent is related to $D_{s}$, the local fractal dimension of the rough surface by the expression $(6)$ :

$$
D_{s}=d-\alpha
$$

where $d$ is the space dimension where the surface grows. Values of $\alpha$ are associated either with jagged surfaces (anticorrelation) or well correlated smooth-textured surfaces, depending on whether they are small or large values, and $D_{s}$ gives information about the degree of surface disorder, surface growth mechanism and surface reactivity.

\subsection{Experimental methods to characterize rough electrode surfaces.}

The fractal behaviour of real systems extends between inner and outer cutoffs which, in many cases, lie in the nanometer range. Therefore, because of its high lateral resolution and 3D images in real space STM imaging becomes extremely useful to characterize rough conducting fractal surfaces. Note that STM methods require the absence of overhangs in order to obtain a complete information about the surface topography.

The dynamic scaling theory provides an useful approach to characterize this type of disordered surfaces. As reported elsewhere (7) the dynamic scaling theory can be straightforwardly applied to STM data as $\xi^{1}=\xi_{\text {stm }}^{1}$, i.e. $\xi_{\text {stm }}^{1}$ is the root mean square roughness determined by STM scans (Fig. 3 ) in the $i$-direction $(i=x, y)$. More explicitly, the following proportionality can be used (7):

$$
\xi_{s t m}^{1}\left(L_{s}\right) \propto\left[1 / L_{s} \sum\left[h\left(x_{1}-h_{s}\right]^{2}\right]^{1 / 2}\right.
$$


where $h_{s}$ is the average height of the deposit profile of length $L_{s}$ determined through the STM scan in the i-direction. Thus, by changing the film thickness, $\delta$, the value of exponent $\beta$ can be obtained from the proportionality:

$$
\xi_{s t m}^{1}\left(L_{s}\right) \propto \delta^{\beta}
$$

Besides, by determining the rms of h-fluctuations over each STM scan segment of length $\mathrm{L}_{s}$ in the $\mathrm{i}$-direction, exponent $\alpha$ can be evaluated from the proportionality:

$$
\xi_{s t m}^{1} \propto L_{s}^{\alpha}
$$

The capability of the method was tested by analyzing a number of self-affine fractal surfaces with known values of $\alpha$ generated by a random áddition algorithm (8). It was found that for typical file sizes used in STM (250x250) the method underestimates $\alpha$ value for $\alpha>0.5$. The deviation of the calculated $\alpha$ with respect to the expected $\alpha_{\text {th }}$ (Fig.4) can be progressively cancelled by increasing the file size, i.e. to $400 \times 400$ or $1000 \times 1000$. However, STM files of these sizes would require such a long acquisition time that the own drift of STM imaging would introduce image distortion. Thus, a STM $256 \times 256$ file was used and then $\alpha$ value was corrected with the plot shown in Fig.4. In this way, the true $\alpha$ value of the real rough surface can be obtained.

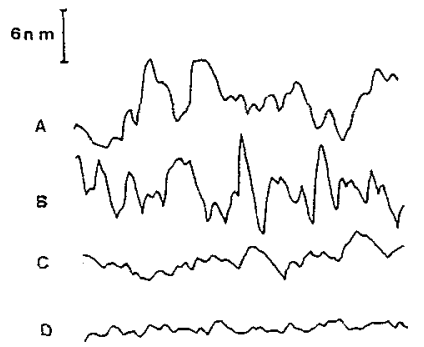

Figure 3. Typical STM scans $(974 \mathrm{~nm})$ recorded in the $\mathrm{x}$-direction for vapour deposited gold films of different $\delta$ values; A) $\delta=$ $850 \mathrm{~nm}$, B) $\delta=500 \mathrm{~nm}$, C) $\delta=160 \mathrm{~nm}$, D) $\delta=30 \mathrm{~nm}$.

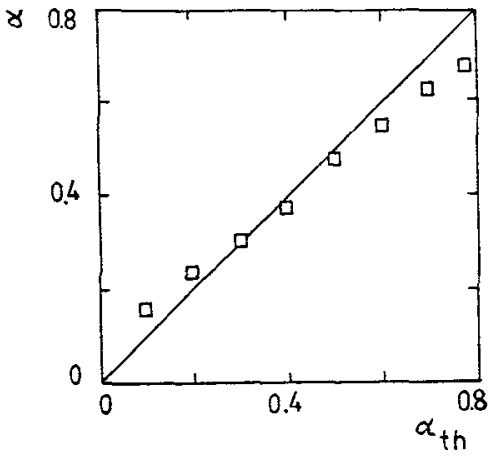

Figure 4. Dependence of the calculated $\alpha$ on $\alpha_{t h}$, the expected $\alpha$ value, for different self-affine fractal surfaces computergenerated on a $256 \times 256$ grid. Data taken from Ref. (9). 
The dynamic scaling method was applied for the quantitative characterization of vapour deposited gold films on smooth glass. These films exhibit a columnar structure with crystalline preferred orientation in the (111) direction (10). The corresponding voltammograms run in $0.5 \mathrm{M} \mathrm{H}_{2} \mathrm{SO}_{4}$ at room temperature resemble those obtained for Au(111) single crystals. STM images of the evolution of these surfaces with different film thicknesses show up the development of random fluctuations as $\delta$ increases due to a competition effect on the growth of columns (20 nm size). For each gold film the value of $\xi$ measured from STM images increases with $\delta$, the average gold film thickness or time obeying equation [7] (Fig.5), but after a certain time has elapsed a steady state surface profile is reached, so that equation [8] can be used to obtain $\alpha$. Typical $\log \xi_{\text {stm }}$ vs $\log \mathrm{L}_{s}$ plots resulting from STM images of vapour deposited gold film with $500 \mathrm{~nm}<\delta<850 \mathrm{~nm}$ made in the $x$-direction show two linear regions with a crossing point at $\log \xi_{s t m}^{\mathrm{x}}=0$ and $\log \mathrm{L}_{\mathrm{s}}=1.6$ and a saturation region for $\log \mathrm{L}_{s}>2.6$ (Fig.6). The slopes of the straight lines are $0.73 \pm 0.1$ for $\log L_{s}<1.6$, and $0.36 \pm 0.06$ for $1.6<L_{s}<2.6$. The evaluation of $\alpha$ made in the slow scan $y$-direction gives similar results, although data in the $y$-direction, are considerably influenced by both drift effects and noise arising from low frequency mechanical vibrations. Therefore, measurements made in the fast $x$-direction are recommended to estimate $\alpha$ by this procedure.

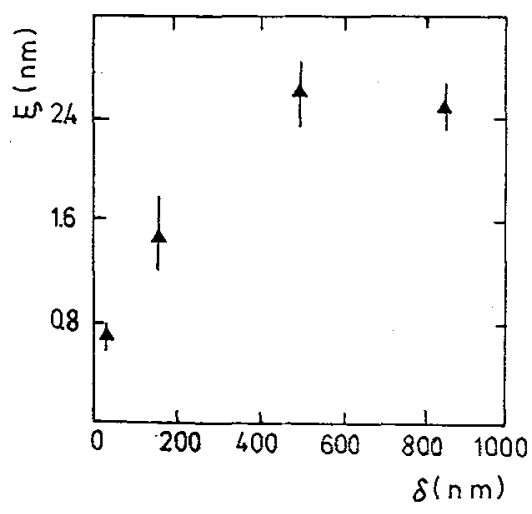

Figure 5. Dependence of limiting $\xi_{\text {stm }}$ value on $\delta$, the average film thickness of vapour deposited gold films. Data taken from Ref. (7).

The average corrected value of $\alpha$ resulting from a large number of STM images of evaporated gold films with $500 \mathrm{~nm}<\delta<850 \mathrm{~nm}$, is $\alpha=0.90 \pm 0.05$ for $\log \mathrm{L}_{\mathrm{s}}<1.6$, and $\alpha=0.36 \pm 0.05$ for $\log L_{s}>1.6$. The value $L_{s}=38 \mathrm{~nm}$ is very close to $d_{s}$, the average columnar size of the deposit. The fact that for $L_{s}<d_{s}$, the value of $\alpha$ is close to 0.9 , suggests that the columnar surface approaches the behaviour of a smioth surface $\left(D_{s} \cong 2.1\right)$.

Rough surfaces become smooth as surface diffusion contributes to eliminate irregularities smaller than $l_{d}$, the diffusion length of surface atoms, which is 


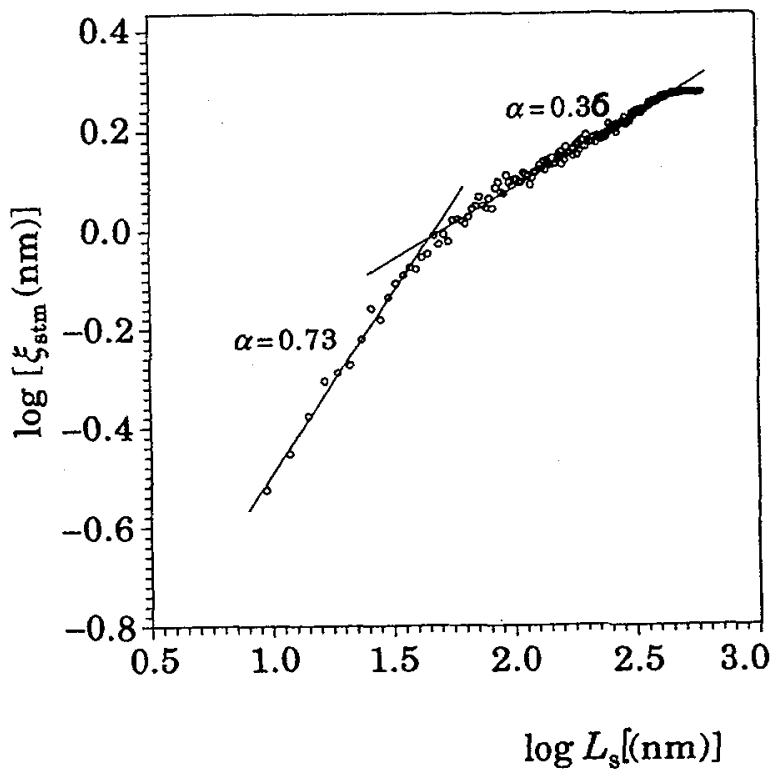

Figure 6. Log $\xi_{\text {stm }}$ vs $\log \mathrm{L}_{\mathrm{s}}$ plots from STM scans in the $x$-direction for a vapour deposited gold film, $\delta=850$ nm. Reproduced with permission from Ref. (7).

close to $d_{s}$ value. On the other hand, for $L_{s}>d_{s}$, the value of $\alpha \cong 1 / 3$ indicates that for lengths larger than the columnar size, the deposit surface behaves as a rough self-affine fractal surface $\left(D_{s} \cong 2.67\right)$. For $L_{s}>d_{s}$, the value $\alpha=1 / 3$ agrees with those resulting from large scale computer simulations of $3 D$ deposits generated by ballistic models at incident angles near the normal to the substrate without surface restructuring (4). Thus, simple ballistic models account for the surface properties of evaporated metal films at scale lengths larger than the columnar size.

Smooth gold surfaces can be easily modified by electrodepositing a conducting polymer such as poly(o-toluidine). The growth of this polymer on gold from $0.65 \mathrm{M}$ o-toluidine containing electrolyte solutions, as concluded from potentiostatic current transients, involves the nucleation and growth of $3 D$ nuclei under surface reaction control (11). As a relatively thick polymer layer is produced the initial flat topography of the substrate is no longer observed. In constrast, the polymer lajer exhibits compact structures and rough surface regions that consist of globular units (Fig.2). The application of the scaling dynamic method to these images results in linear $\log \xi_{\text {stm }}^{\mathrm{x}}$ vs $L_{s}$ plots with $\alpha=0.70 \pm 0.05$ for $L_{s}<10 \mathrm{~nm}$, and $\alpha=0.33 \pm 0.05$ for $\mathrm{L}_{\mathrm{s}}>10 \mathrm{~nm}$. The corrected $\alpha$ values are $\alpha=0.85$ for $\mathrm{L}_{\mathrm{s}}<10 \mathrm{~nm}$ and $\alpha=0.33$ for $\mathrm{L}_{\mathbf{s}}>10 \mathrm{~nm}$. The value $\mathrm{L}_{\mathbf{s}} \cong 10 \mathrm{~nm}$ is close to the average size of globular elements. These figures point out that the surface of globular elements $\left(L_{s}<d_{s}\right)$ approaches an euclidean behaviour $\left(D_{s}=2.15 \pm 0.05\right)$, whereas the surface of the agglomerates formed by the globular elements $\left(L_{s}>d_{s}\right)$ exhibit a self-affine surface $\left(D_{s}=\right.$ 
2.66 \pm 0.05$)$. The value of $\alpha \cong 1 / 3$ agrees with the prediction of the Eden model without restructuring (4) according to which all surface sites have the same probability of growth. The Eden model has been used to simulate growth processes controlled by surface reactions, for instance, the growth of poly(o-toluidine) films by electrodeposition on gold.

Dynamic scaling was also applied to analyze STM images of columnar gold electrodeposits grown from the electroreduction of hydrous gold oxides formed on polycrystalline gold electrodes (Fig.2) (12). In this case, the $\log \xi_{\text {stm }}$ vs $\log L_{s}$ plots resulting from STM images, taken in $x$-direction for film thicknesses ranging between 100 and $10000 \mathrm{~nm}$, also shows two linear regions with a crossing point at log $L_{s} \cong d_{s}$, the average size of the rounded elements forming the gold film structure (Table 1)(13). The values of $\alpha$ derived from these plots for $L_{s}\left\langle d_{s}\right.$ and $L_{s}>d$ for gold films of different thicknesses are assembled in Table 1 . As in the case of

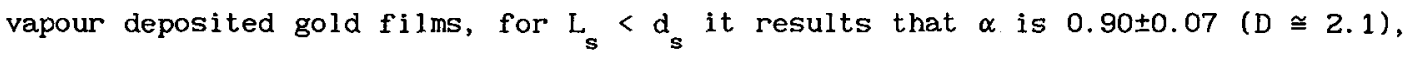
i.e gold atom surface diffusion produces a smooth columnar surface, whereas for $L_{s}<$ $d_{s}$ it results $\alpha=0.49 \pm 0.07$.

Table I

Data derived from the application of the dynamic scaling to STM images of columnar gold electrodeposits.

$\begin{array}{rccc}\delta & \alpha & \alpha & d_{s} \\ \mathrm{~nm} & \mathrm{~L}_{\mathrm{s}}<\mathrm{d}_{\mathrm{s}} & \mathrm{L}_{\mathrm{s}}>\mathrm{d}_{\mathrm{s}} & \mathrm{nm} \\ 100 & 0.96 \pm 0.07 & 0.43 \pm 0.09 & 24 \\ 160 & 0.89 \pm 0.09 & 0.41 \pm 0.05 & 25 \\ 500 & 0.91 \pm 0.06 & 0.50 \pm 0.06 & 30 \\ 560 & 0.89 \pm 0.04 & 0.50 \pm 0.06 & 32 \\ 2800 & 0.93 \pm 0.07 & 0.52 \pm 0.07 & 49 \\ 9100 & 0.90 \pm 0.06 & 0.51 \pm 0.08 & 50 \\ 11500 & \underline{0.86 \pm 0.06} & \underline{0.45 \pm 0.06} & 79 \\ & \alpha=0.90 \pm 0.07 & \alpha=0.49 \pm 0.07 & \end{array}$

\subsection{Electrochemical behaviour of rough electrode surfaces.}

The influence of surface diffusion on the stability of rough surfaces has been revealed by ageing columnar gold electrodes in $\mathrm{H}_{2} \mathrm{SO}_{4}$ at $50{ }^{\circ} \mathrm{C}$ for $10^{4} \mathrm{~s}$ (14). In this case $D_{\mathbf{s}} \cong 2.1$ was observed for all scale lengths. The change from a rough surface $\left(D_{s} \cong 2.5\right)$ to a smoother surface $\left(D_{s} \cong 2.1\right)$ can be easily followed by the decrease in $R$, the surface roughness factor, determined voltammetrically as function of ageing time $(12,14)$. The ageing process obeys the kinetic laws expected for a particle growth process under surface diffusion control (14). 
The impedance spectra of rough surface electrodes also present apparently anomalous features when compared to smooth surface electrodes. As early reported (15) the impedance spectra can be described by

$$
Z(\omega)=A(i \omega)^{-s}
$$

where $A$ is a frequency-independent parameter, $i=(-1)^{-1 / 2}, \omega$ is the angular velocity $(\omega=2 \pi f) f$ is the frequency) and $\alpha$ is $a$ number between 0 and 1 . In the absence of faradaic processes $Z(\omega)$ is given by $(i \omega C)^{-1}$, where $C$ is the capacity. Then, exponent $s$ can be determined from a $\log \omega C$ vs $\log \omega$ plot. For smooth surface electrodes it results $\alpha \cong 1$ whereas for rough fractal surfaces $\alpha$ differs from 1 . The estimated $s$ values for columnar gold electrodeposits in $10^{-3} \mathrm{M} \mathrm{H}_{2} \mathrm{SO}_{4}$ and $\omega>2.5 \mathrm{KHz}$ are in the 0.7-0.75 range as expected for rough surfaces. However, at present a correlation between $s$ and $D_{s}$ values can not be established $(16,17)$. The frequency dispersion observed for the surface of columnar gold electrodeposits arises from

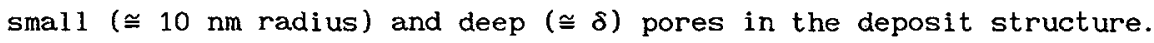

The kinetics of a diffusion controlled electrochemical reaction on rough columnar gold surfaces has been studied under potentiostatic conditions (18). It is known that the kinetics of reactions occurring at fractal self-affine or at self similar surfaces exhibit a peculiar behaviour which reflects the fractal characteristics of the surface. This is the case for a rather simple reaction such as the $\left[\mathrm{Fe}\left(\mathrm{CN}_{6}^{-4}\right] /\left[\mathrm{Fe}(\mathrm{CN})_{6}^{-3}\right]\right.$ electrooxidation reaction under diffusion control at fractal electrodes (16). The relationship between current ( $I$ ) and time ( $t$ ), under a constant potential step in the diffusion controlled regime, is given by:

$$
i \propto t^{-n}
$$

with

$$
\mathrm{n}=\left(\mathrm{D}_{\mathrm{s}}-1\right) / 2
$$

It should be noted that for a smooth surface $\left(D_{s}=2\right)$ it results $n=0.5$. On the other hand, for fractal surfaces the value of $n$ differs from 0.5 , as it is shown in the $\log I$ vs $\log t$ plots resulting from columnar gold electrodeposits (Fig.7). From these measurements $n$ results 0.72 yielding $\alpha=0.56$ and $D_{s}=2.44$, in well agreement with those derived from the STM analysis for $L_{s}>d_{s}$ (Table 1 ).

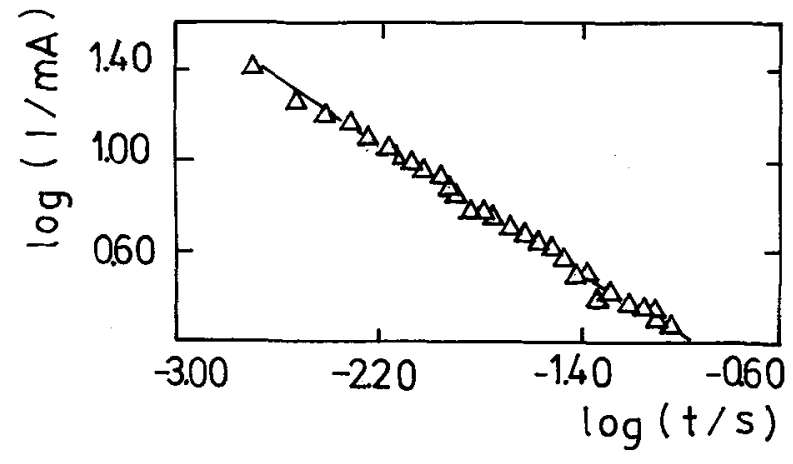

Figure 7. Log $I$ vs $\log t$ plot for the diffusion controlled current transient corresponding to the $\left[\mathrm{Fe}(\mathrm{CN})_{6}\right]^{4-}$ to $\left[\mathrm{Fe}(\mathrm{CN})_{6}\right]^{3-}$ electrooxidation reaction on a columnar gold electrodeposit $(R=$ $50)$. The slope of the straight line is $\mathbf{n}=0.72$. Data taken from Ref. (18). 
Finally note that the value $\alpha \cong 0.5\left(D_{s} \cong 2.5\right)$ obtained for the columar gold electrodes can not be explained by growth models described in the literature. Further theoretical work is required for a complete understanding of the surface growth mechanism operating in the electroreduction of hydrous metal oxides.

\section{ISOTROPIC STRONG DISORDER}

\subsection{Dendritic metal electrodes}

A dendritic surface can be taken as a model of those surfaces with isotropic strong disorder. The topography of these surfaces approaches that of a "metal forest" (Fig. 8) resembling closely those produced by computer simulation of diffusion limited aggregation (DLA) models (19). In terms of fractal geometry, these surfaces are "self-similar fractals" (2) with a large contribution of overhangs. In this case either the deposit surface and the deposit mass are fractals or the deposit surface is i fractal and the deposit a mass non-fractal (1).

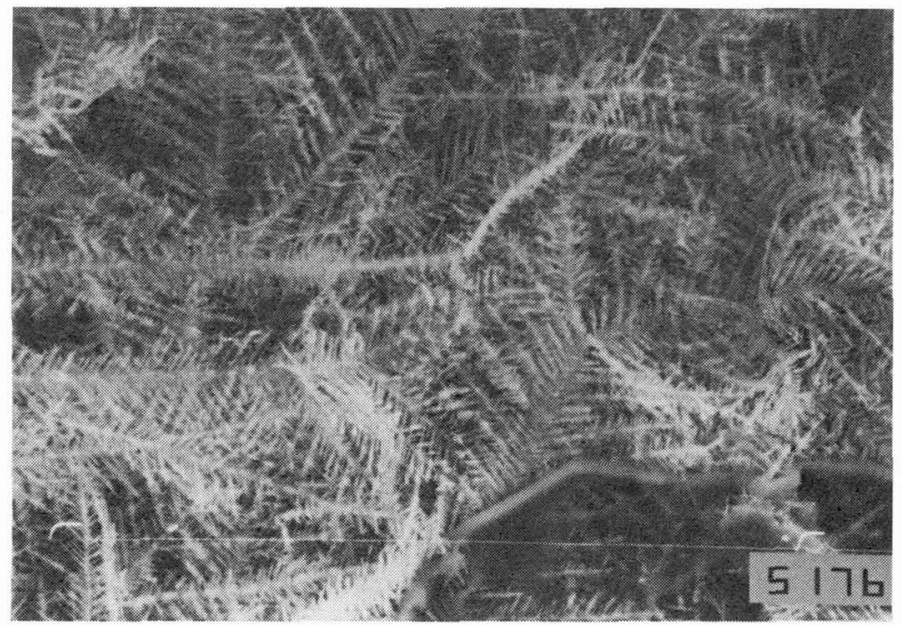

Figure 8. SEM micrograph of the surface of silver dendrites electrodeposited on platinum at $\mathrm{E}_{\mathrm{d}}=$ $-0.200 \mathrm{~V}$ from $0.50 \mathrm{M} \mathrm{Na}_{2} \mathrm{SO}_{4}+0.010 \mathrm{M} \mathrm{H}_{2} \mathrm{SO}_{4}+0.005$ $\mathrm{M} \mathrm{Ag}_{2} \mathrm{SO}_{4} \cdot(x 1000)$.

\subsection{Experimental methods to characterize dendritic electrode surfaces.}

The fractal characterization of self-similar deposits can be made by applying different experimental methods. For mass fractals one of these methods concerns the determination of $M$, the deposit mass, and $R$, the radius of gyration of the growing deposit (19). $M$ and $R$ are related through $D_{M}$, the mass fractal dimension, by 


$$
M \propto R^{\mathrm{D}}
$$

$M$ is usually obtained from the electrodeposited charge by using Faraday's law, and $R$ is estimated from high quality images of the deposit. Thus, $\log M$ vs $\log R$ plots can be used to estimate $D_{M}$. Conversely, for surface fractals with non-fractal mass, $D_{s}$ can be evaluated from $A$, area and $V$, volume data by the following equation:

$$
\text { A } \alpha v^{D / 3}
$$

The value of $A$ can be obtained from the underpotential deposition voltammogram of a foreign metal ( $\mathrm{Pb}, \mathrm{Cd})$ used as a yardstick, and the value of $\mathrm{V}$ can be calculated from the electrodeposited charge density $q$.

\subsection{The influence of mass transport on the development of dendritic surfaces.}

A typical example of this type of measurements is given in Fig. 9 for a dendritic silver electrodeposit grown at constant potential $E_{d}=-0.20 \mathrm{~V}$ vs a saturated calomel electrode (SCE) from $10^{-3} \mathrm{M} \mathrm{Ag}_{2} \mathrm{SO}_{4}+0.5 \mathrm{M} \mathrm{Na}_{2} \mathrm{SO}_{4}+10^{-2} \mathrm{M} \mathrm{H}_{2} \mathrm{SO}_{4}$ (20).

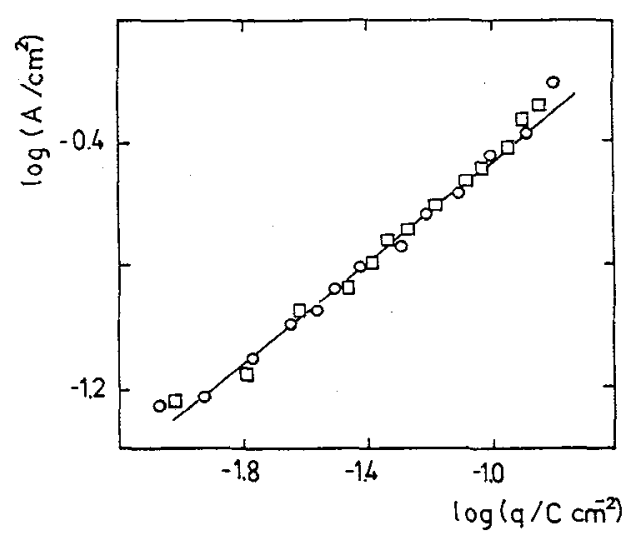

Figure 9. $\log A$ vs $\log q$ plot for a silver electrodeposit grown on a hemispherical platinum electrode at $E_{d}=-0.200 \mathrm{~V}$ in $0.50 \mathrm{M} \mathrm{Na}_{2} \mathrm{SO}_{4}+$ $0.010 \mathrm{M} \mathrm{H}_{2} \mathrm{SO}_{4}+0.005 \mathrm{M} \mathrm{Ag}_{2} \mathrm{SO}_{4}$ at $25^{\circ}$ C. Reproduced with permission from Ref. (21).

The slope of the linear $\log A$ vs $\log q$ plot gives $D_{s}=2.5 \pm 0.03$ in agreement with the expectations of DLA models (19), whereas the linear log $q$ (or M) vs $R$ plot yields $D_{M}=3$. This means that the silver deposit grown under these conditions behaves as a surface fractal with a non fractal mass. The deviation from the straight 1 ine observed in $\log A$ vs $\log \mathrm{V}$ plot for $\log \mathrm{q}>-1$ is due to a change in the growth mode of the silver deposit from isotropic to anisotropic produced by convection (21). Note that equations [12] and [13] apply only to self-similar fractals so that they are not applicable to anisotropically growing deposits which result in self-affine fractals. Therefore, convection restricts the range of isotropic growth in aqueous solutions. This is an important reason for the use of 2D electrochemical cells for the growth of dendritic deposits. 3D isotropic metal dendritic deposits in 3D cells can be produced by employing a gellified 
conducting solution (22). The contour of the silver dendritic electrodeposits formed at $\mathrm{E}=-0.30 \mathrm{~V}$ from $10^{-3} \mathrm{M} \mathrm{Ag}_{2} \mathrm{SO}_{4}+0.5 \mathrm{M} \mathrm{Na}_{2} \mathrm{SO}_{4}+10^{-2} \mathrm{M} \mathrm{H}_{2} \mathrm{SO}_{4}+0.5 \mathrm{~g}$ Agarose/100 $m l$ for different electrodeposition times, $t_{d}$, grows isotropically (Fig. 10).

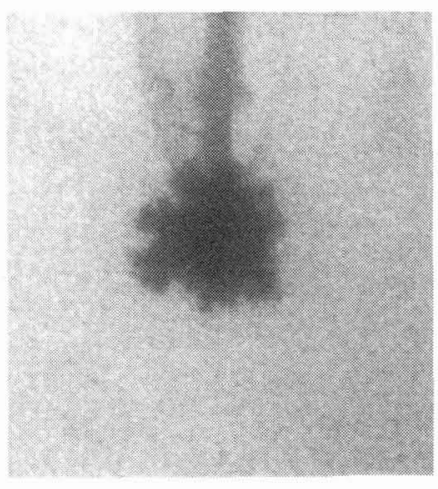

a

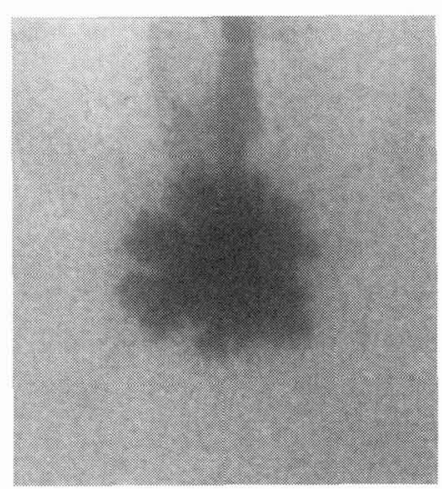

b

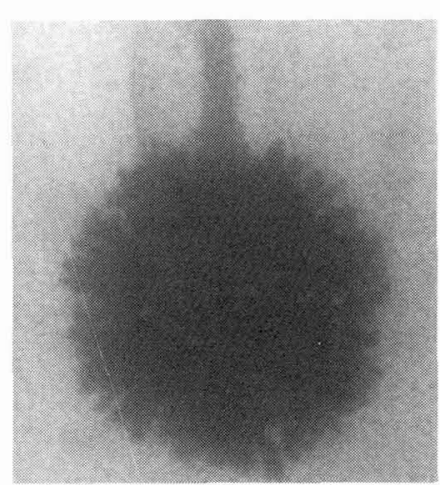

c

Figure 10. Contour of a 3D silver dendritic electrodeposit grown on a hemispherical Pt at $E_{d}=-0.30 \mathrm{~V}(\mathrm{SCE})$ from $10^{-3} \mathrm{M} \mathrm{Ag}_{2} \mathrm{SO}_{4}+0.5 \mathrm{M} \mathrm{Na}_{2} \mathrm{SO}_{4}+10^{-2} \mathrm{M} \mathrm{H}_{2} \mathrm{SO}_{4}+0.5 \mathrm{~g}$ Agarose $/ 100 \mathrm{ml}$ for different electrodeposition times, (a) $t=1169 \mathrm{~s}$, (b) $t=1645$ s, (c) $4334 \mathrm{~s}$.

This deposit is formed by microscopic dendrites leading to an open structure. The $\log Q$ vs $\log R$ plot resulting from these runs covering the $-0.3 V \leq E_{\alpha} \leq 0.1 \mathrm{~V}$ range (Fig. 11), shows a reasonable straight 1 ine up to $\log R \cong-0.6(R \cong 0.25 \mathrm{~cm})$.

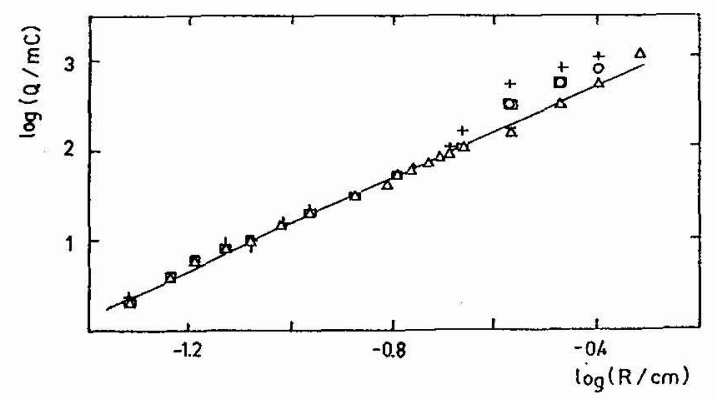

Figure 11. Log Q vs log R plot for silver electrodeposits obtained in $0.50 \mathrm{M} \mathrm{Na}_{2} \mathrm{SO}_{4}+0.010 \mathrm{M} \mathrm{H}_{2} \mathrm{SO}_{4}+$ $0.005 \mathrm{M} \mathrm{Ag}_{2} \mathrm{SO}_{4}+0.5 \mathrm{~g} \mathrm{Agarose} / 100$ ml at different $E_{d}$ values. ( $\left.\Delta\right) E_{d}=$ $-0.30 \mathrm{~V},(+) \mathrm{E}_{\mathrm{d}}=-0.20 . \mathrm{v},(0)$ $E_{d}=0 \mathrm{~V},(\square) E_{d}=0.10 \mathrm{~V}$.

From the slope of this line it results $D_{K} \cong 2.5 \pm 0.1$, i.e. in the gellified medium the silver deposit behaves as a mass fractal and, obviously, as a surface fractal with $D_{s}=2.5 \pm 0.1$. The deviation observed for $R>0.25 \mathrm{~cm}$ is probably related to an increase in the compactness of the object. The formation of a mass fractal silver electrodeposit is consistent with DLA patterns observed from cross-section 
photographs. The $R$ vs $t$ plots obtained for $-0.2 V \leq E_{d} \leq 0.1 \mathrm{~V}$ show that the radial velocity increases with $E_{d}$. This fact should be related to the role played by the electric field in growth kinetics, even in the presence of supporting electrolyte. The same experiments run in the same media in the absence of the supporting electrolyte have shown an enhanced influence of the electric field in the growth process leading to the development of a denser deposit. The $\log R$ vs $\log Q$ plots drawn from these data yield a straight line with $D_{M}=3$. Therefore, these results allow us to conclude that the greater the contribution of migration to the kinetics of metal electrodeposition the larger the trend to the formation of dense patterns with non fractal mass (23).

The influence of diffusion and electric potential radial fields on the morphology of aggregates was modelled through $2 \mathrm{D}$ Monte Carlo simulations in a 640x640 square lattice. Briefly, growth pattern formation under a constant external field implies that particles are released at a large distance from the growing centre and follow a random walk $(24,25)$ either in the absence of electric field ( 1 initing particle trajectory dimension, $D_{p}=2$ ) or in a preferred radial directional (biased walk) (25) imposed by an electric field $\left(D_{p}=1\right)$. When a particle sticks to the surface of the growing center it becomes a part of the aggregate. For $D_{p}=2$ and $D_{p}=1,0 \%$ and $100 \%$ biased particle displacements, respectively were assigned. Snapshots resulting from 2D Monte Carlo simulations for 0 and 100 percent biased particle displacements correlates closely with experimental patterns resulting from solutions with and without supporting electrolyte, respectively, Log $N$, the number of particles in the cluster, vs $\log R$ plots obtained at different stages of the aggregation process have allowed us to derive the values of $D_{M}$ for $2 D$ clusters. These values change from the $D_{s}$ value for a DLA pattern in $2 D$ to that of a dense radial pattern as the percentage of the biased particle displacement in the calculation is increased. As expected, $D_{M}$ values compatible with DLA patterns are only obtained when the biased contribution to the particle movement approaches zero. Correspondingly, the Monte Carlo simulation keeps a good correlation with the experimental data.

\section{CONCLUSIONS}

Columnar and dendritic metal electrodeposit surfaces can be taken as models for the study of irregular surfaces with anisotropic and isotropic strong disorders. The use of fractal geometry allows us to obtain relevant information about the degree of surface disorder, the surface growth mechanisms and also to predict the kinetics of electrochemical reactions at these complex surfaces. 


\section{ACKNOWLEDGEMENT}

This research project was financially supported by the Consejo Nacional de Investigaciones Cientificas y Técnicas and the Comisión de Investigaciones Científicas de la Provincia de Buenos Aires.

\section{REFERENCES}

1) Pfeifer P. and Obert M. in "The Fractal Approach to the Heterogeneous Chemistry". J. Wiley, New York, (1989), p 11 and references therein.

2) Mandelbrot B.B., in "The Fractal Geometry of Nature", W. H.Freeman, New York (1982).

3) Gouyet J.F., Rosso M. and Sapoval B., in Fractals and Disordered Systems, Bounde A. and Havlin S. Eds, ,Springer-Verlag, Berlin, (1991) p.231.

4) Family F., Physica A, 168, (1990) 561.

5) Vicsek T., Fractal Growth Phenomena, World Scientific, Singapore (1989).

6) Family F and Vicsek T, J. Phys. A, 18, (1985) L75.

7) Salvarezza R.C., Vázquez L., Herrasti P., Ocón P., Vara J.M. and Arvía A.J., Europhys.Lett., 20, (1992) 727.

8) Voss R.F. in Fundamental Algorithms in Computer Graphics, Earnshaw E. A. Ed., Springer Verlag, Berlin, (1985).

9) Vázquez L., Salvarezza R.C., Herrasti P., Ocón P., Vara J.M. and Arvia A.J., Appl.Surf. Sci. in press.

10) Herrasti P., Ocón P., Vázquez L., Salvarezza R.C., Vara J.M. and Arvia A.J., Phys. Rev. A, 45, (1992) 7440.

11) Herrrasti P., Ocón P., Vázquez L., Salvarezza R.C., Vara J.M. and Arvia A.J., in preparation.

12) Vázquez L., Bartolomé A., Baró A.M., Alonso C., Salvarezza R.C. and Arvia A.J., Surf.Sci., 215, (1989) 171.

13) Vázquez L., Salvarezza R.C., Herrasti P., Ocón P., Vara J.M. and Arvia A.J., submitted.

14) Alonso C., Salvarezza R.C., Vara J.M., Arvia A.J., Vázquez L., Bartolomé A. and Baró A.M., J. Electrochem. Soc., 137, (1990) 2161.

15) de Levie R., Electrochim. Acta, 9, (1964) 1231.

16) Pajkossi T., J.Electroanal.Chem., 300, (1991) 1.

17) Gómez M., Vázquez L., Salvarezza R.C., Vara J.M. and Arvia A.J., J.Electroanal.Chem., 317, (1991) 125.

18) Ocón P., Herrasti P., Vázquez L., Salvarezza R. C., Vara J.M. and Arvía A.J., J. Electroanal. Chem., 319, (1991) 101.

19) Meakin P., in "The Fractal Approach to the Heterogeneous Chemistry". J.Wiley, New York, (1989), p 131. 
20) Hernández-Creus A., Carro P., González S., Salvarezza R.C., and Arvia A.J., J. Electrochem. Soc., 139, (1992) 1064.

21) Hernández-Creus A., Bolzan A.E., Carro C., González S., Salvarezza R.C., Marchiano S.L. and Arvia A.J., J.Electroanal.Chem., 336, (1992) 85.

22) Hernández-Creus A., Carro P., González S., Salvarezza R.C., Marchiano S. L. and Arvia A.J., submitted.

23) Hernández-Creus A., Carro P., González S., Salvarezza R.C., Marchỉano S. L. and Arvia A.J., submitted.

24) Witten T.A. and Sander L.M., Phys.Rev. Lett., 47, (1981) 1400.

25) Meakin P., Phys. Rev. B, 28, (1983) 5221. 